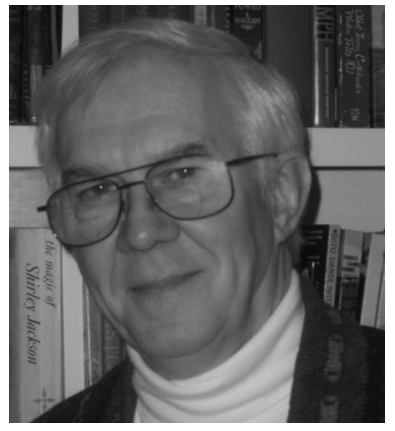

\section{Surfin’ Australasia}

When my wife, Helen, and I took a four-week tour of Australia, New Zealand, and Fiji, it was my intention to conduct the editorial business for Optical Engineering on the road. I had even contemplated taking along our iSight video camera and my PowerBook, so that we could visit our children and grandchildren. Alas, a late e-mail from our tour director established the reality of such arrangements. Connectivity in Australasia is not quite what it is in the US. Thus, it was clear that my editorial goal of assigning papers to our Associate Editors within two days was not going to be as easy as I had anticipated. In fact, I was not able to meet the goal after the first few days.

Once in Australia, there were surprises. The biggest one was the variation in the cost of connection to the Web. A week before taking the tour we made a "granddaughter" trip to Virginia and on our way home to Atlanta we sat out tropical storm Jeanne in Charlotte, North Carolina. This worked out nicely since Tom Suleski, one of my PhD students, and Alan Kathman of Digital Optics took us out to a good Italian restaurant that evening and Jeanne passed over us that night. The surprise came when we checked into a modest-priced Drury Inn and found that the internet connection was free.

For many 4-star and 5-star hotels in Australasia, the internet connection is part of their "business center." The center is usually two dinky PCs with no printer connection that are either coin-operated (Alice Springs) or accessible from a password on a scratch-off card (Melbourne). Those hotels that offered laptop connections in the room charged \$18 US/day (Sydney and Auckland). The most expensive connection was, as one might expect, at a resort. In Fiji, one PC in the lobby cost $\$ 25 / \mathrm{hr}$ !

I was able to keep in touch, but just barely. While visiting Brian Orr at Macquarie University in Sydney, I was able to borrow some bandwidth and download about 10 days of messages (50 e-mails and 700 pieces of spam) while we went to lunch and Deborah Kane showed me the impressive electro-optics laboratories at the Department of Physics.

The most useful and cheapest way of keeping in touch during the tour was the internet cafe, where \$1.50 US got me an hour on a PC. There may be internet cafes that are a combination of your home DSL link and a Starbucks, but the ones we frequented Helen described as "dives." They were either up or down several flights of stairs and consisted of rows of carrels with PCs and some screaming kids playing networked computer games.

Back in the US, the Sheraton near LAX charged \$11 for a day to connect my laptop in my room. Not as low as the Drury Inn, but approaching a reasonable cost for connection. And the next day, on our final leg home from Los Angeles to Atlanta, I read in USA Today that Best Western, Holiday Inn, Marriott's Residence Inn, and Omni are including it in the price of a room. So high-speed internet connections are becoming a competitive feature for hotels and motels within the US. There is no doubt that our favored means of communication on the road has changed over the years...even on vacation. During our tour we bought no postcards and made no phone calls while we were away. We kept in touch by e-mail and browsers. Eventually this ease and low cost of communication may extend to the Australian outback and the resorts of Fiji. 